MedieKultur | Journal of media and communication research | ISSN 1901-9726

Article

\title{
Consumption that matters
}

\section{Sophie Esmann Andersen \& Carsten Stage}

MedieKultur 2010, 49, 151-170

Published by SMID | Society of Media researchers In Denmark | www.smid.dk The online version of this text can be found open access at www.mediekultur.dk

The purpose of this article is to contribute to the understanding of a rising mode of ethical consumption by exploring the brand concept (RED) and its intertwinement of commerce and charity. Based on an analysis of central online media texts, we focus on: 1) the campaign's "cool" visual and verbal structures of appeal, and 2) the discursive struggle concerning the ethical potential of consumption motivated by the campaign. The analysis is followed by a discussion of the potential and problems of (RED) as a way of handling global responsibility for distant suffering others. We argue that from a perspective focusing on the representation of the distant sufferer, (RED) can be criticised for transforming suffering into aesthetic spectacles in order to legitimise hedonistic consumption. The potential of the campaign is that it acknowledges that effective ethical ways of relating to distant others will have to be integrated into the narratives of self and community circulating in a given context.

\section{Media, suffering and compassion fatigue}

According to sociologist Luc Boltanski, contemporary media users in developed societies very often find themselves in a difficult situation that creates an ethical dilemma. This situation occurs on a daily basis when media users view human suffering at a distance by means of media technologies (Boltanski, 1999). In other words, users are continuously confronted with images of human suffering caused by war, natural or man-made catastrophes, famine 
and economic inequality, which they cannot ease directly by offering some sort of physical help. The viewers' inclination to act depends therefore on the level of affect that these images are able to create or the emotional depth of the connection established between the suffering person(s) and the interiority of the viewer(s). Only if the images "get to me", "move me" or "grab me by the throat" will I act by speaking or paying, which according to Boltanski are the two main possible responses available for the viewer of distant suffering.

The ethical relation between viewers and distant sufferers is precarious. Indeed, it may never even be established because no footage of the suffering is available. Alternatively, the pictures available may not be strong enough to move anyone. Perhaps the media telling the stories fail to tell them in an appealing or committed way (Chouliaraki, 2006). Perhaps the sufferers are not people that the viewers normally care about. Or perhaps the viewers are faced with the suffering at a bad time, when other issues or catastrophes are calling more urgently for their attention. This clearly underlines the fact that watching suffering does not necessarily create a state of ethical care or complicity between victim and witness (Ellis, 2001). The face of the victim must not only be transmitted to become ethically demanding - it must also be mediated in a certain way, making the suffering person ethically important (Butler, 2004; Chouliaraki, 2006). The circumstances, the mediation and the type of victim have to be just right if media users are to care about and respond to suffering.

Another highly debated threat against the enabling of a mediated ethical relation between sufferer and viewer is the amount of visible suffering that modern media users are confronted with on a daily basis. Discussions concerning a rising "crisis of pity" (Boltanski, 1999; Chouliaraki, 2006), "numbness" towards mediated suffering (Sontag, 2003), or a contemporary alertness towards "the fragility of empathy" (Dean, 2004) all focus on the fact that our ability to care for other people is blatantly exploited in contemporary media culture. In this article we will not discuss the correctness of these concerns about the incapacity of the media to create healthy social relations between viewers and distant sufferers. Instead, we want to investigate some of the ways in which these concerns are being handled in new types of charity work in which empathy and the images of suffering are clearly and systematically set aside as a way of relating to media users and distant others. In other words, we argue that an awareness of the risk of exhaustion and lack of interest in mediated suffering is detectable in many new ways of doing charity work. A host of different more rational, hedonistic or interpersonal transactions between helper and helped (e.g., child sponsorships) is simply blossoming, introduced by and framed within a marketing discourse. As such, speaking and paying/donating are no longer the only ways to respond in order to confront distant suffering - people can also choose to consume.

\section{Marketised philanthropy in consumer culture}

One of the most predominant discourses in contemporary businesses is the discourse of responsibility (e.g., Paine, 2003). Corporations are faced with the increasing demand to act 
responsibly, and must constantly address their own social responsibility and act accordingly by creating not only financial value and growth for shareholders, but also social, cultural and symbolic value for all stakeholders (employers, local communities, supplier chains, NGOs, society at large, consumers etc.). In other words, corporations have entered a discourse of strategic ethics, thus creating new disciplines and practices for marketing and other management disciplines (Kotler \& Lee, 2005). A major cluster of reasons why corporations engage in social responsibility is driven by market positioning and brand logic (Paine, 2003). By acting responsibly and addressing ethical issues, corporations can imbue their brand with ethical values, thus capturing a position as an ethically responsible actor in the marketplace, e.g., via social marketing or cause-related marketing initiatives (Kotler \& Lee, 2005), and creating a strong value for consumers to consume. Such marketing initiatives encourage consumers to take an ethical stand in their consumption practices under the motto "the more I buy, the more money is raised for people in need". Thus, these social marketing initiatives transform the concept of the well-known politically and ethically conscious consumer, who is traditionally known by his buy-cotting behaviour (e.g., Sørensen, 2004), into what can be termed a marketised philanthropist. The social marketing initiatives do not frame the consumer within a discourse of political activism or rebellious resistance (Lang, 2006), but rather within a discourse of hedonism and aesthetics: it is not about consuming less, but consuming more. Being good is about indulging oneself in the world of goods.

The aim of our article is to investigate the communicative strategies and ethical discussions that are played out in relation to one interesting example of these new ways of intertwining business and ethics or charity; namely the cause-related brand concept (RED). Conceptually speaking, cause-related marketing (CRM) initiatives frame three social actors (Adkins, 1999): the companies, the consumers and the cause, with the last of the three often involving a non-specified group of distant others. Recent research within causerelated marketing has primarily focused on the corporate aspect of the practice, and thus on CRM as a strategic practice: for enhancing corporate image in general (Chattanano et al., 2008); for building a strong, socially responsible corporate image (Baghi et al., 2009); for strengthening long-term consumer brand-relation bonds (Katsioloudes et al., 2007); or for enhancing sales responses in a more short-term perspective (Larson et al., 2008). Within this corporate perspective, there is a highly prioritised focus on the effect of CRM initiatives and thus on the framing of the discipline within a strategic management discourse (Tsai, 2009). A second stream of research within cause-related marketing adopts the consumer perspective, thus building a case regarding consumer responsibility (Caruana \& Crane, 2008) or ethical brands and everyday consumption (Szmigin et al., 2007). The consumer perspective also integrates evaluations of consumer response strategies towards CRM initiatives (e.g., Youn \& Hyuksoo, 2008). The third and far less researched stream of cause-related marketing research has focused on the effect of these initiatives from the cause perspective, thus thematically approaching the cause as the main subject of concern, e.g., within human trafficking (Arthurs, 2009) or breast cancer (Harvey \& Strahilevitz, 2009). Finally, a fourth 
stream of research into CRM adopts a contextual perspective, reflecting upon questions of cultural impact regarding CRM initiatives (e.g., Salzer-Mörling \& Strannegård, 2007; Nickel \& Eikenberry, 2009).

In relation to these four research perspectives, our paper adopts a transversal perspective as we analyse discursive (verbal and visual) strategies ascribed to the concept as well as contextual ethical positions contested by (RED), thus focusing on the dilemmas in the relation between the brand, the consumer and distant others. The transversal perspective provides insights into understanding the relational intertwinements of the company-consumer-cause positions as both an arena for creating potentially new forms of relations and a contested space of ethical struggles. We will argue that (RED) discursively establishes nonaffective ways of relating to consumers and, furthermore, it facilitates both new relational strategies between companies and consumers and ethical struggles between a variety of social actors, who understand the ethical potential of consuming in different ways. Contrary to the existing research on cause-related marketing initiatives, this paper considers (RED) as initiating a new ethical economy (Arvidsson \& Peitersen, 2007). Consequently, rather than explaining economic effectiveness from either a corporate, consumerist or cause perspective, this paper will analytically discuss the ethical problems and potentials embedded in hedonistic consumption practises and the struggling dilemmas imposed hereto, which emerge in the fusion of commerce, consumption and distant others. The transversal perspective adopted in this paper and the notion of the (RED) sphere as a contested space of ethical struggles are substantiated by the use of a discourse theoretical approach in analysing the case, which will be presented in the following.

\section{Empirical material and method}

(RED) was first launched in the United Kingdom in January 2006 by the artist and activist Bono, in cooperation with American politician and Global Fund representative Bobby Shriver, as a new approach to generating awareness and ensuring donations for a worthy cause by setting up a branded licensing company. From a branding perspective, (RED) is rather unique in the sense that it has been created or constructed with the specific purpose of raising money for HIV/AIDS-infected Africans. To achieve this aim, (RED) positions itself between philanthropy and commerce as it collaborates with a number of iconic brands ${ }^{2}$ in a co-branding effort to raise awareness of the African HIV/AIDS epidemic and to obtain donations for the Global Fund earmarked for Africans in need. The cause-related marketing idea behind (RED) is that licensed partner companies donate a percentage or a part of their (RED) product profits to the Global Fund, and benefit from their involvement by enhancing their good standing with the public, thus ensuring their legitimacy. In addition to directly supporting the cause by providing funds for the purchase of HIV/AIDS medication generated by the sales of specific (RED) products, the partner companies pay for and carry out all marketing of their own (RED) products. 
In this article, we are particularly interested in investigating two dimensions of the (RED) campaign. Firstly, we want to analyse how the campaign verbally and visually addresses its audience and tries to persuade this audience to perform charitable actions. We do this by looking at the campaign's key texts and videos. Secondly, we want to analyse the responses to the campaign and the debates and discussion that it has raised. Here we primarily explore the Internet-based campaign Buy (less) Crap, which takes a critical standpoint concerning the (RED) campaign. We focus on this oppositional decoding to highlight that (RED) has been a highly contested CRM phenomenon. Of course many consumers have embraced the concept and rhetoric of (RED). According to the campaign website, 150 million dollars have been raised to the benefit of suffering people in Africa, and YouTube is filled with consumer video responses, which express support towards the (RED) concept. But substantial criticism has also been raised - for instance targeted at the enormous amount of money used on advertising by the campaign. ${ }^{3}$ For that reason, it is not sufficient just to look at the way (RED) encodes its project or the numbers indicating that (RED) has had a positive effect. To understand the transformative potential of (RED), you also have to take the ethical dilemmas and discussions surrounding the campaign into account. A conflict-oriented analysis of (RED) can furthermore contribute to a broader understanding of CRM as a tendency motivating discursive struggles over the relation between ethical actions and consumption. In other words, the dilemmas and antagonisms expressed in relation to (RED) can also be of help when trying to grasp the ethical discussions played out in relation to other CRM concepts. Our main interest is consequently twofold: 1) To understand the way the (RED) campaign discursively relates to the potential consumer of (RED) products, and 2) To investigate the ethical negotiations and discursive struggles which surround this campaign. After analysing these two different dimensions of the (RED) campaign, we end the article by discussing the different potential for and problems of (RED) as a way of handling global responsibility for distant suffering others.

The reasons for examining the (RED) concept are its impact and ability to raise money and the level of debate and reactions to which it has given rise. ${ }^{4}$ We simply argue that the campaign has had a high degree of cultural effect, which can be traced in the very large amount of user responses on different social media platforms (e.g., YouTube) to new (RED) initiatives. (RED) especially seems to be effective when it comes to communicating a certain way of addressing global inequality, which means that as a media phenomenon the campaign functions in a "ritual" way by establishing shared beliefs concerning how to react to distant suffering among a large group of users (Carey 1989). By combining the allocation of money from rich to poor/sick with the consumption of luxury products, (RED) has had a broad appeal motivating actions as well as protests. So the concept is a very fruitful object of investigation because it allows us to analyse a variety of textual material directly addressing the intertwinement of charity and consumption as both an ethical solution and an ethical problem. By looking at the discursive construction and negotiation of (RED), we 
try to create a clearer picture of contemporary ethical discussions and positions linked to the intertwinement of charity and consumption.

Our method of analysis is based on a discourse-theoretical approach inspired by the classical concepts of Ernesto Laclau and Chantal Mouffe in Hegemony and Socialist Strategy (1985). As we see it, their interest in analysing discursive struggles and floating signifiers is very useful when describing the different ways of articulating the relation between consumption and ethics in our empirical material. A discourse theoretical approach thus contributes to our analysis by offering a set of concepts that make it possible to describe, in a precise way, differences in the circulating understandings of ethical consumption. Discourse theory is simply a very helpful method when it comes to conducting the above-mentioned conflict-oriented analysis of (RED) as a cause-related marketing phenomenon.

Discourse and articulation are defined by Laclau and Mouffe in the following way: "We will call articulation any practice establishing a relation among elements such that their identity is modified as a result of the articulatory practice. The structured totality resulting from the articulatory practice, we call discourse" (Laclau \& Mouffe, 2001, p. 105). Discourses are structured totalities of articulatory practice that create a chain of equivalence relating signifiers to each other. As an example, the signifier "ethical consumption" can be semantically related to a chain of equivalence consisting of signifiers such as "egoism" and "profit maximisation" thereby giving it a certain negative content. However, the chain of equivalence can also consist of positive signifiers like "win-win-situation" or "global responsibility". When various discourses create different chains of equivalence in relation to a central signifier (e.g., "ethical consumption"), the latter is turned into a "floating signifier". Following Laclau and Mouffe - who are inspired by the work of Jacques Derrida - the established discourses characterising a certain social field are inherently unstable and unfinished. Therefore, the meaning of signifiers and the discourses used to understand reality are constantly renegotiated, naturalised, destabilised and fought over (Andersen, 1999; Frello, 2003; Jørgensen \& Phillips, 1999; Laclau \& Mouffe, 2001). During these struggles, certain signifiers are often at the centre of the discussion because they are articulated in different ways or integrated in different discourses. When a certain signifier is articulated differently as a part of a discursive struggle, Laclau and Mouffe, as mentioned, call it "a floating signifier". This is why we see "ethical consumption" as a floating signifier that is invested with different meanings by different discourses. The intertwinement of consumption and charity is simply at the heart of a discursive struggle in which discourses create different structured totalities of articulatory practice. And it is this struggle that we want to investigate.

The concept of discursive multimodality and multimediality as described by Günther Kress and Theo van Leeuwen is also interesting for our study (Kress \& van Leeuwen, 2001). Here discourses are described as independent of mode (e.g., speech, moving images, sound and writing) and media (e.g., television, Internet, newspaper) in the sense that a certain discourse is not linked to a certain modality or media. Related to the field of branding and marketing, 
this means that an ethical discourse of a brand identity can be reproduced both in a webpage (involving graphical features, speech, music and pictures) and in other media (such as posters involving pictures and written text), or even through humans as media (e.g., word-of-mouth).

\section{Analysis}

In our analysis of (RED), with a specific focus on message communication mediated through the webpage www.joinred.com, three tendencies are salient. The first tendency is the almost total absence of imagery of suffering people. Instead, the people benefiting from the campaign are transformed into digits (the number of people who have received help) or abstract figures. The second tendency is the focus on social impact, legitimising the fact that consumption can be intertwined with doing good and helping suffering people. The third tendency is the constant repetition of the idea that (RED) creates a win-win-winsituation by benefiting corporations, consumers and suffering others alike. (RED) is simply a solution to what is described as an old dilemma between fulfilling desires and being virtuous. These three tendencies will be unfolded below.

\section{Suffering vs. impact}

The suspension of suffering in favour of focusing on social impact as a way of motivating charitable actions is clearly present in the textual presentation and manifesto of (RED).

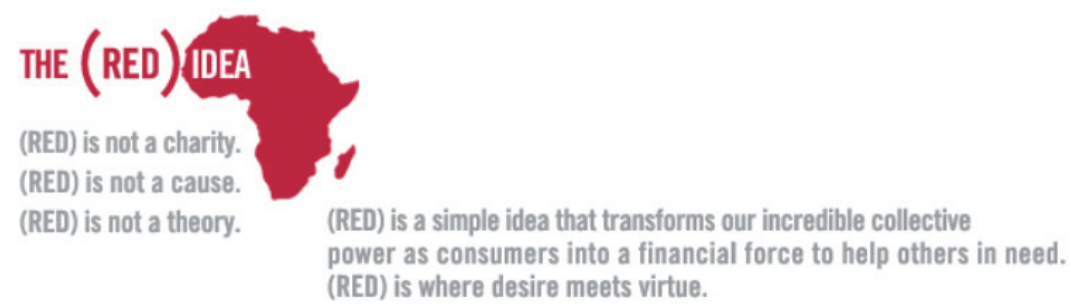

Every time you choose to buy a (RED) product or service, at no extra cost to you, the company who makes that product will give up to fifty-percent of its profit to buy and distribute antiretroviral medicine to our brothers and sisters dying of AIDS in Africa.

Every dollar goes straight to Africa. Straight to the people who need it. Straight to keeping them alive so that they can go on taking care of their families and contribute socially and economically to their communities.

The most sought-after brands in the world have become (RED) partners. American Express, Apple, Converse, Dell, Emporio Armani, Gap, Hallmark, Starbucks, Nike and more have recognized that (RED) is an idea that is right for their brands, their consumers and the world today.

(RED) is an answer to an emergency. An answer that is working. In just two years, so many people like you have made the choice to buy (RED) products, that over 4 million African lives have been greatly impacted. 
The (RED) idea begins by defining its own genre, explaining that (RED) is not a charity, cause or theory, but a "simple idea that transforms our incredible collective power as consumers into a financial force to help others in need". In other words, the text uses impact and efficiency as the primary way of appealing to the reader. The consumer should simply participate in the (RED) concept because it "is an answer to an emergency. An answer that is working. In just two years, so many people like you have made the choice to buy (RED) products that over 2.5 million African lives have been greatly impacted". As such, the use of an emotional appeal to create responses or the creation of a link between the suffering person and the interiority of the helper is suspended. The reason for helping is that the actions are effective; they actually change the life conditions for people out there, thus creating an argument based on simple causality and logic.

In their book The Ethical Economy (2007), Adam Arvidsson and Nicolai Peitersen detect a general shift in the way of understanding value in contemporary economies. One of their main points is that companies today have to legitimise themselves ethically in order to be able to create profit. Their licence to operate simply depends on fulfilling certain ethical standards and having an overall positive social impact. From this point of view, the logic of accumulating profit is supplemented by a "logic of matter", with companies also competing to create the most positive social consequences. The logic of matter is important not only from the companies' perspective (e.g., in terms of marketing and corporate image), but also from the consumers' perspective. On their homepage, (RED) has developed an "impact calculator", by which the positive social consequences of buying (RED) products can be measured: the consumer costs of the (RED) products are translated into the numbers of lives saved.

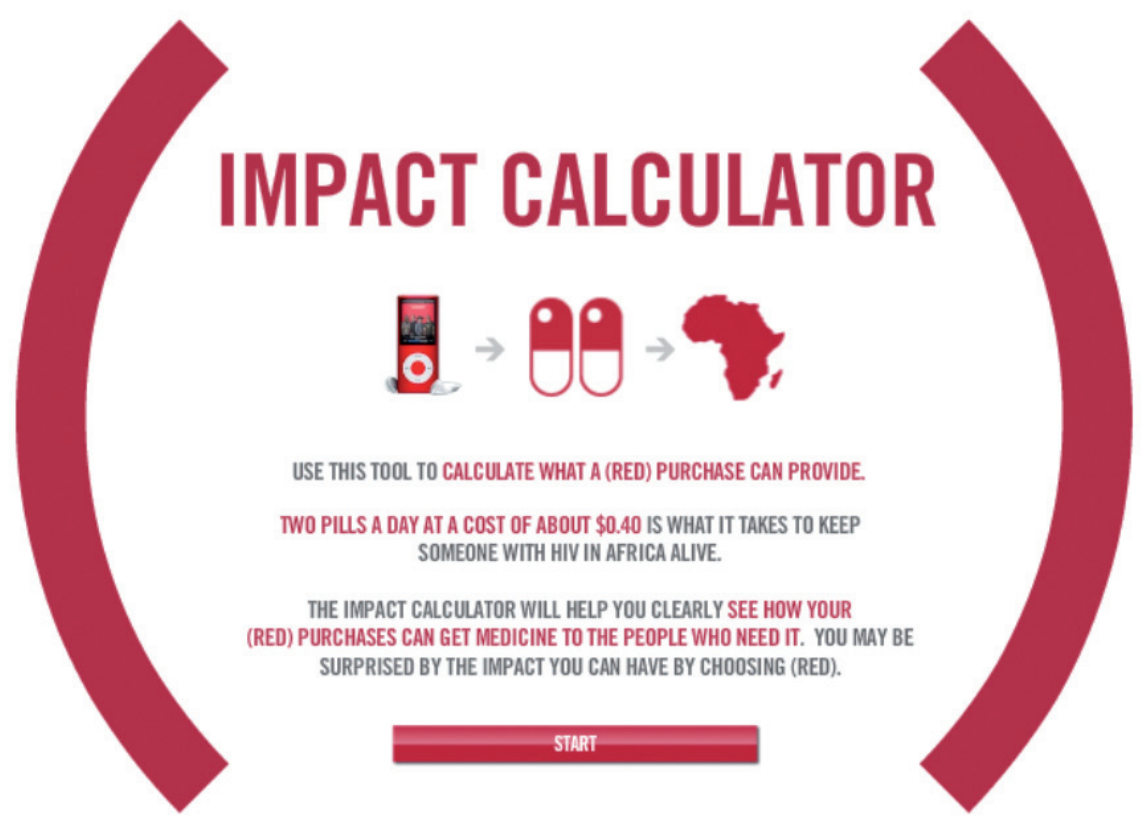

The (RED) Impact Calculator 
When you choose a (RED) iPod and a (RED) Dell laptop and ask the calculator to start calculating, you get the following message: "Your purchases can provide lifesaving medicine for / 1 month \& 4 days for someone living with HIV in Africa / and remember that all of your (RED) purchases help save / the lives of people with HIV in Africa". The consumption of luxury products is thus translated into positive social impact in an extremely tangible way. This is done in order to show how buying luxury products should not be regarded as selfish hedonism (or egoism), but - using "a logic of matter" - rather as a rational way of combining consumption and ethics.

The coolness and rationality of the campaign seems first of all to confront the more empathy-oriented strategies of other charity campaigns, which focus on compassion and pity (e.g., SOS Children's Villages). Within this empathic framework, the motivation to act is closely linked to the sensual/visual experience of the Other, representing an ethical and affective invocation (Butler, 2004; Deleuze, 2005; Levinas, 1996). The avoidance of suffering is prominent in the video-based communication of the (RED) concept. Compared with consumer video responses promoting (RED) on YouTube, where the wretched faces and bodies of Africans are repeatedly used in the attempt to create involvement ${ }^{5}$, the official (RED) videos clearly follow a more rational line of thinking. One of the official videos shows a completely abstract explanation of the (RED) concept $^{6}$, while others visualise transformations from misery to recovery by documenting the local impact of the campaign? ${ }^{7}$. Another group of videos shows celebrities and companies in their common quest to promote (RED). This dimension consists, among other things, of more traditional advertising material and reports by celebrities visiting Africa (Christy Turlington in Swaziland and Elle Macpherson in Ghana) ${ }^{8}$, as well as famous "talking heads" explaining why they support the campaign (e.g., Gisele Bündchen, Natasha Bedingfield, Joss Stone) $)^{9}$.

One of the rare depictions of suffering individuals can be found in the video called The Lazarus Effect, in which before and after pictures of three HIV patients (Silvia, Nigel and Elimas) are shown while a voiceover explains how the (RED) concept has been able to transform the lives of the three individuals..$^{10}$ The shift from the first "state of misery" to the second "state of recovery" is communicated visually by means of a slowly diffusing transition between still pictures of the suffering Silvia, Nigel and Elimas to still pictures of the recovering Silvia, Nigel and Elimas. This is done without a clearly marked cut between "before" and "after" the treatment, thereby creating a feeling of fruitful growing or resurrection (cf. the Lazarus metaphor). In addition, the first still picture is in black and white, while the depicted person gains colour in the second still picture, thereby enhancing the effect of revitalisation. Suffering is therefore not used very much to motivate affect-based reactions, and the consumer is not supposed to help because he/she feels sorry for a person, but because he/she wants to participate in (RED)'s revitalisation project. 


\section{Virtuous desire}

This leads us to the third tendency: the idea of (RED) as a transgression of the juxtaposition between virtue and desire. When it comes to traditional charity or donation scenarios based on renunciation, the giver and the receiver are by definition not the same person, since the donating subject is acting as the sender of an object (aid), which is received by another subject or group of subjects. This equation of subject and sender is nevertheless precisely the thing that those charity projects combining consumption and donation challenge. Whilst the traditional donor inhabits a giver position, the cause-related consumer or "causumer" may best be described as occupying a giver/receiver position, since the act of consuming is both a way of helping others and a way of buying into a universe of symbolic values for self-performance and for satisfying personal (com)passions, desires and needs. Thus, the ethical value created by consumption practice points not only towards the distant suffering of others, but also inwards towards the consumer and towards his relation to others. In other words, the ethical values become symbolic values which help to create and maintain a certain sense of self, and which (e.g., through the distinctive colour of red) are recognisable within specific settings of consumer culture. This is not least explicated by the representation of the (RED) consumer. Thus, by buying into the ideology of (RED), the consumer is literally imbued with the values of (RED) - or rather embraced by the goodness of (RED), as it transforms the consumer into an upgraded (YOU): Consuming (RED) ${ }^{T M}$ equals becoming (YOU) $)^{\text {RED }}$.

(RED) presents the equation of consuming and helping as a solution. At last it is possible to buy, enjoy and orchestrate your self and appearance without being unethical or selfish. Using (RED) you can become a good-looking altruist, hence depriving aesthetic desires of their negative aura of egoism and selfishness. Thus we argue that (RED)'s articulation of "ethical consumption" creates a chain of equivalence linking it to signifiers such as "simplicity", "rationality", "virtuous desire", and "positive impact", thereby totally deconstructing the opposition between consuming and doing good. Ethics as a matter of morality, obligations and duties are transformed into a marketised and aestheticised practice as will be described below.

Summing up, (RED) articulates the relation between ethics and consumption as nonproblematic to the extent that charitable actions enabled by consumption can no longer be understood as charity. The distinction between charity and consumption is simply deconstructed and presented as unimportant in this new business model. A different articulation of the relationship of ethics and consumption is also present - although more indirectly. The brands involved in the (RED) campaign still include the traditional non-(RED) goods, in which ethical concerns for the distant suffering others play no role, as main products. And this duality is explicated because the consumer is presented explicitly with a choice: You can either buy the non-(RED) product and NOT save lives, or you can buy (RED) products 
and save lives. It is, as the (RED) presentation quotes, "That simple". From this point we see an articulation in which consumption is not directly linked to ethics because consuming non-(RED) products is all about buying the things you want - nothing else. Being "that simple", the choice between (RED) and non-(RED) is not really an option. Or rather, buying non-(RED) products is articulated as the unethical or non-ethical choice, thereby opposing a traditional discourse of consumption, where the act of buying is linked to "personal needs" and "value for money".

\section{Buylesscrap.com}

(RED)'s intertwinement of consumption (buying (RED) products), self-representation (consumers becoming "red") and helping suffering people (facilitating aid) has attracted both attention and critique. A very clear example of a critical voice is the anti-(RED) promotion Buy (less) crap, which defines the traditional donation as the proper or more ethically correct way of managing social and global responsibility. The project's homepage has the following text as its headline:

Shopping is no solution. Buy (Less). Give more. Join us in rejecting the ti(red) notion that shopping is a reasonable response to human suffering. We invite you to donate directly to the (RED) campaign's beneficiary The Global Fund and to these other charitable causes... without consuming (www.buylesscrap.com).

Basically, Buy (less) crap articulates a relationship of incongruence between shopping/ consuming and helping suffering people. According to the text entitled "Mission" on the campaign homepage, the goal of the campaign is twofold: 1) To remind us that the most efficient way of supporting a cause is to donate directly to the receivers or a non-profit organisation, and 2) to "inspire less consumption overall".

The idea of the necessity of buying less and being more modest is underlined by the aesthetic design of the homepage. Three pictures of naked people in dislocated settings with words like "(RED)ICU(LESS)", "MEANING(LESS)" and "POINT(LESS)" written over their bodies are shown.

The focus on the word "less" and the nakedness of the people seem to suggest a certain striving for constraint in relation to consumption. Buy (less) crap thus seems to promote and prefer the traditional transactional charity logic, adopting a non-receiving subject/ sender position. However, the campaign does not explain clearly why consumption is perceived as a problem in itself. Is it due to problems of inequality between the consumerist Western countries and the Third World? Or because of problems of sustainability making it necessary to consume less than usual? Many reasons could be mentioned, but the campaign seems to presuppose a certain amount of knowledge which is never made explicit.

The campaign homepage also contains a letter to Bobby Shriver, the founder of (RED), 


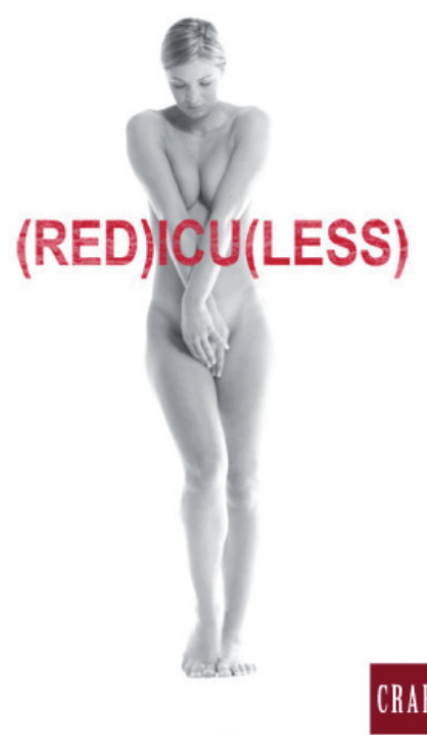

in which three dimensions concerning (RED) are criticised: 1) Its lack of administrative transparency. Here the concern seems to be that it is impossible to see how much money has been spent on, for instance, advertising and promotion of all sorts, or who receives money for their activities; 2) You cannot see how much money each purchase generates for the Global Fund. What is criticised is that the consumer cannot know the extent to which the companies involved support the fund substantially or merely contribute a minimal share of the overall profit; and 3) (RED) does not stress the opportunity of donating directly to the Global Fund.1" In other words, you have to buy in order to help, which according to Buy (less) crap is a problem. In order to correct this, the homepage contains a section linking directly to the aid organisations. The point seems to be that the privileged should give things away rather than buying new things, because buying does not effectively solve the problem of global inequality. Compared to the two ways of articulating a relationship between ethics and consumption mentioned above, Buy (less) crap thus marks a third position. Here a chain of equivalence is created between "ethical consumption" and "lack of transparency", "inefficiency", "selfishness", "profit maximisation" and "global inequality". In contrast to (RED), consumption is not considered as having great ethical potential. And in opposition to traditional logic, where consumption is only about fulfilling personal needs, the Buy (less) crap campaign emphasises that the creation of an ethical relationship between rich and poor is threatened precisely by patterns of consumption.

\section{Discussion: the problems and potentials of (RED)}

In the final part of this article, we will address and discuss the problems of and potential for (RED). One of the main dilemmas raised by the (RED) concept is whether or not the avoidance of images of suffering should be understood as a way of recognising the African 
receiver as a non-victimised equal, or rather as a way of neglecting the factual differences in living standards between the consumers and the receivers. Are we witnessing an upgrading of the distant others because the campaign is unwilling to present them as passive victims? Or is the campaign yet another example of Western citizens failing to acknowledge the powerlessness and poor living conditions of Africans, thereby ignoring the role of Western consumption in the upholding of these asymmetries?

This dilemma is very evident when analysing one of the most iconic photos used to promote (RED), namely an American Express (RED) advert showing supermodel Gisele Bünchen and the Masai goatherd and warrior Keseme Ole Parsapaet.

The advert focuses on the win-win-win-logic by showing the three winners gaining something through the (RED) transaction: 1) the hedonistic consumer (cf. "My card"), 2) the African receiver gaining something from the act of consuming (cf. "My Life"), and 3) the company represented by the red plastic card. A positive reading of the photo would

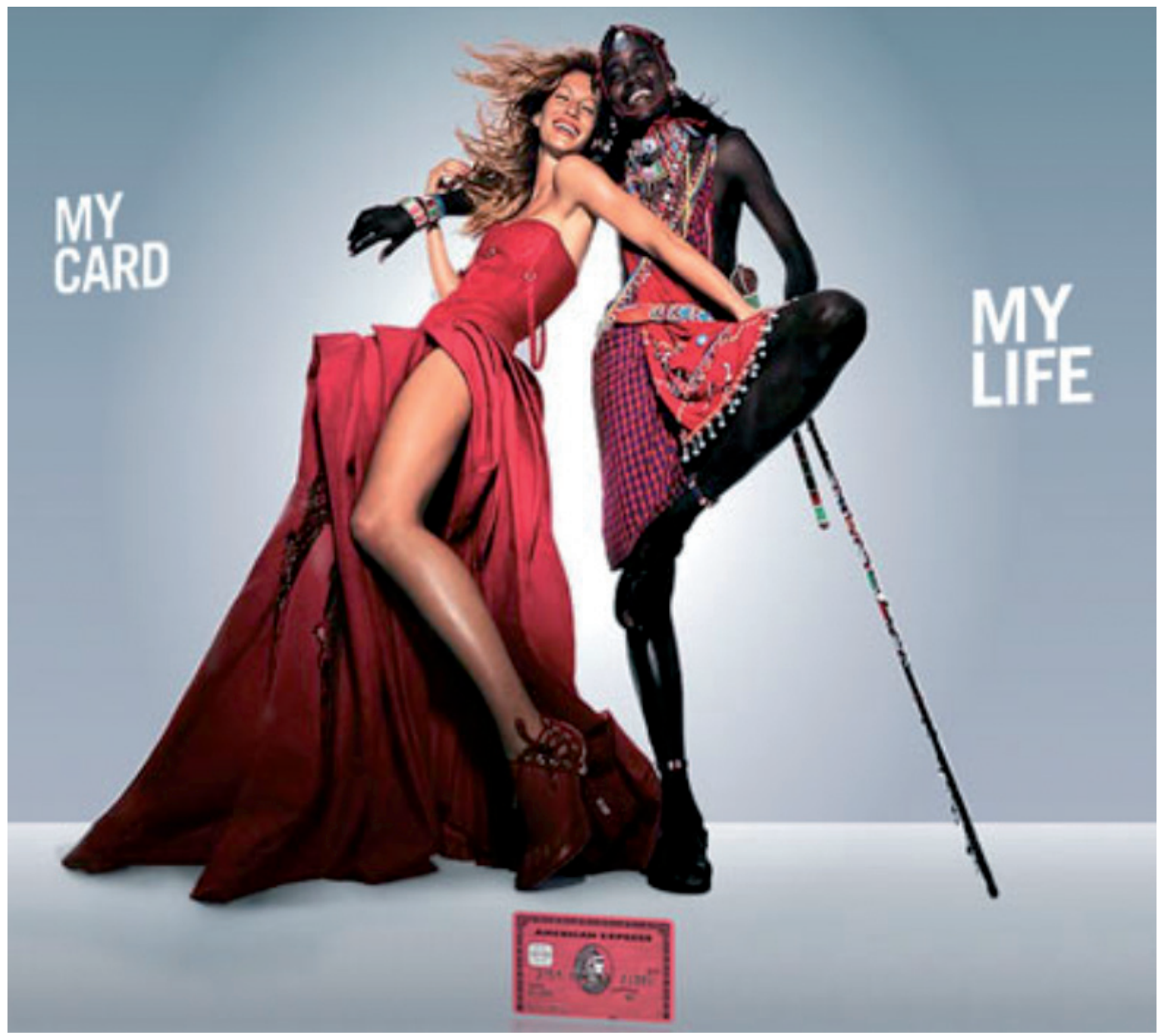

American Express (RED) advert 
underline the way the Masai man is equalised or raised to the same level as the model. She is beautiful and glamorous and so is he; he is, so to speak, the incarnate dream of the revitalised beautiful other in the (RED) concept. A negative reading would instead stress the absurdity of using this kind of idealised imagery in order to represent the receiver position in the transaction offered by (RED). The real receiver is a sick and probably extremely poor human being - not an idealised exotic and smiling other. ${ }^{12}$ In this perspective, the Masai is rather used to satisfy the viewer's aesthetic fantasies of an African other - and to legitimise the act of consuming - not to recognise the receiver.

In other words, the question raised by the picture is whether it recognises the miserable situation of the suffering Africans or glosses over the responsibility of the West in the creation of global inequality by idealising, aestheticising and exoticising the receiver. In his book Media and Morality (2007), Roger Silverstone introduces an ideal for the representation of distant others, which is interesting in this context. This ideal he calls "proper distance", and it entails that the representing individual should always try to be aware of both the dimensions connecting the representing and represented individual (e.g., their humanity) and the real cultural, social and economic differences between them. If the other becomes too different, the representation supports an immorality of distance according to Silverstone; but if he/she becomes too much like the representing social actor, an immorality of sameness is the result. The picture - and the overall avoidance of visual suffering in the (RED) campaign - could thus be described as creating an immorality of sameness precisely because it ignores the discrepancies and power relations between the helper and the helped. In this way the consumer is protected from a more fundamental question that could grow out of the visual experience of suffering: Is it OK for me to spend a lot of money on luxury products when people out there could be saved by the money I use to entertain myself? Don't I have a moral obligation to donate as much as possible instead of transforming my donation into a small, positive side-effect of my banal acts of consumption?

In many ways we find this type of questioning and critique in relation to (RED) highly relevant. There seems to be a lack of proper distance when it comes to raising awareness of the real social conditions of the suffering Africans. Another suitable critique is raised by Ponte, Richey and Babb in their analysis of (RED), which stresses that (RED) does not in any way ensure that the production leading to the reallocation of profit is ethically defensible. In particular, the authors mention two of the companies involved - Converse/Nike and GAP - as having very problematic histories of sweatshop allegations (Ponte, Richey \& Babb, 2009, p. 308). In this way (RED) makes it possible for "[e]xtremely competitive practices and/ or exploitative relations of production and trade" to "be justified ex-post by 'doing good"' (Ponte, Richey \& Babb, 2009, p. 303). In other words, the authors underline the necessity of focusing not only on the level of redistribution, but also on the level of production when evaluating the contemporary intertwinements of consumption and charity.

Even so, taking a pragmatic perspective on the campaign might help us to highlight some of its potential as well - potential that is linked to the way consumption and iden- 
tity construction are used as mobilising forces in the egalitarian redistribution of money. According to sociologist John Tomlinson, the ability to create effective social relations of responsibility to distant others depends on the strategic decisions made by social actors trying to raise awareness of global responsibility. Tomlinson's point is that a successful creation of social feelings and acts of global responsibility must somehow appeal to (or engrain themselves into) the cultural narratives and desires of local life itself (Tomlinson, 1999, p. 26). (RED)'s way of tapping into the consumption of popular iconic goods, and the use of the colour red that gives the consumer a certain altruistic glow, is a way of making global responsibility "count" or "desirable" in the local context. The longing for a certain item and the possibility of staging identities is simply activated as a local force supporting the redistribution of money in a globally responsible way. Despite the lack of proper distance, this ability to link hedonism, identity construction and global responsibility underlines the positive potential of the (RED) campaign. It simply shows us that new, responsible ways of linking distant localities do not need to transgress these contexts, but can actually use them as reservoirs of symbolic and cultural material that can be mobilised to the benefit of distant suffering others.

Summing up, our way of responding to the dilemmas raised by the avoidance of suffering and the intertwinement of ethics and consumption in the (RED) campaign would be to distinguish between a representational and a pragmatic focus. From a representational perspective, the lack of proper distance and the highly aestheticised depiction of the African other, as well as the lack of reflection on the pitfalls of capitalistic consumption, are problematic. From a pragmatic point of view, this critique could nevertheless be described as mostly theoretically relevant. Does it matter if the Africans are not represented in a precise way as long as the campaign moves substantial amounts of money into health care and medical supplies for people in need? Is this not simply an example of rich Westerners exercising their privilege to argue against acts that actually help suffering others because of some lack of accuracy in the communication strategy or business concept used? Looking at it from a pragmatic perspective, would there be any good reason for not choosing a (RED) product and buying a similar product from someone else instead?

\section{Conclusion}

In this paper, we have analysed two different dimensions of the (RED) campaign: firstly, the way the campaign tries to motivate acts with a charitable effect, and secondly, the discussion of the ethical potential of consumption motivated by (RED). Using this analysis as a point of departure, we then discussed the problems and potential of (RED).

(RED) clearly suspends suffering as a way of relating to the consumer in favour of a visual and textual focus on social impact and revitalisation. We regard this tendency to block out suffering as being based on the fear of increasing "compassion fatigue" in contemporary media culture, which - from a business perspective - implies that empathy or affect can 
no longer be used as an effective way of creating actions among consumers. Instead, the (RED) campaign underlines the way in which inequality can be erased at the same time as personal desires are being fulfilled. In this way (RED) takes part in the search for new ways of doing charity work that try to avoid relying on affect by engraining themselves into local patterns of behaviour and social relations. From a positive perspective, an element of recognition could be detected in this strategy, because the African other is de-victimised. The avoidance of visual suffering could nevertheless also be interpreted as a way of legitimising the routines of consumption by not confronting the consumer with a "state of misery", which could disturb the necessary act of buying. Following this line of thinking, there is a lurking danger of an immorality of sameness, because the suffering other is idealised as an exotic, smiling receiver in order to maintain the idea that consumption can be a way of confronting social inequality.

In our material we argue that we have found three discourses or ways of talking about the relation between consumption and ethics/charity: 1) A discourse in which consumption is articulated as not being linked with charity, but primarily performed to fulfil personal needs (e.g., non-(RED) products). This discourse is characterised by a non-explicit separation of charity and consumption; 2) A discourse in which consumption and charity can be combined to an extent that charity can no longer be perceived as charity (e.g., the (RED) campaign); 3) A discourse in which charity is articulated as being essentially different from acts of consumption. This third discourse is characterised by an explicit separation of charity and consumption because consumption can never be truly charitable (e.g., Buy (less) crap). In this way we have detected a position in which consumption takes place without ethical concerns, a position in which ethics and consumption are fused in a radical way, and a position in which ethics is defended against consumption.

The problem of (RED)'s intertwinement of consumption and charity is that the more structural inequalities between rich and poor countries - supported by a capitalistic logic of trade and production - are not addressed or reflected on. At the same time, the campaign does not clearly show the extent to which the companies involved help or how much they earn from their affiliation with the campaign. Taking a pragmatic stand, this type of criticism could be accused of focusing too much on demonising capitalism as incongruent with charity, thus overlooking new ethical tendencies and potentials in contemporary Western economies. In our discussion, we have highlighted the fact that (RED)'s main potential for developing new kinds of charitable actions or ethical economies is that it clearly underlines the idea that local cultural desires must be addressed when trying to create effective and globally responsible ways of acting. This stresses that "consumption that matters" has to be ethical consumption which consumers can integrate into the narratives of self and community circulating in a given context.

This "discursive struggle" concerning how to understand the floating signifier of "ethical consumption" is interesting because it shows that the ethical possibilities of consumption are being explored, but that they still meet with a rather large amount of scepticism. 
Although (RED) promotes itself as creating a win-win-situation for consumers and sufferers, the consumer choosing to buy a DELL laptop, an iPod or a pair of Converse shoes is thus also caught in a lose-lose-situation. If the consumer chooses to buy (RED) products, he/ she risks being accused of being an egoistic hedonist who is only ready to help others when something can be gained. If the consumer chooses non-(RED) products, he/she can also be accused of turning down an ethical way of consuming. To this can be added the discourses related to non-buying or buy-cutting behaviour as promoted by the Buy (less) crap-campaign, which constantly negates the motives of ethical consumption per se. In this way the discursive struggle analysed in this article is also a struggle to define how the purely ethical consumer should act. During the process of struggling, this entails that no way of acting in relation to the (RED) campaign can be freed from the accusation of being unethical. This clearly underlines that the success and effectiveness of attempts to combine consumption and ethics are not only a question of how much money is mobilised in favour of people in need, but also of how the meaning and symbolic connotations of initiatives are negotiated and defined through discursive struggles in the local context.

\section{References}

Adkins, S. (1999). Cause Related Marketing. Who cares wins. Oxford: Butterworth-Heinemann.

Andersen, N.Å. (1999). Diskursive analysestrategier. Copenhagen: Nyt fra Samfundsvidenskaberne.

Arthurs, J. (2009). Brands, Markets and Charitable Ethics: MTV's EXIT Campaign. Participations: Journal of Audience \& Reception Studies, 6(2), non pagina.

Arvidsson, A. \& Peitersen, N. (2007). The Ethical Economy. Retrieved November 12010 from the ethical economy website: http://www.ethicaleconomy.com/files/EthicalEconomy_CH1.pdf

Baghi, I., Rubaltelli, E. \& Tedecschi, M. (2009). A strategy to communicate corporate social responsibility: cause-related marketing and its dark side. Corporate Social Responsibility and Environmental Management, 16(1), 15-26.

Boltanski, L. (1999). Distant Suffering. Morality, Media and Politics. Cambridge: Cambridge University Press. Butler, J. (2004). Precarious Life. The Powers of Mourning and Violence. London: Verso.

Carey, J.W. (1989). A Cultural Approach to Communication. In Carey, J.W. (ed.) Communication as Culture: Essays on Media and Society (pp. 11-28). London: Routledge.

Caruana, R. \& Crane, A. (2008). Constructing Consumer Responsibility: Exploring the Role of Corporate Communications. Organization Studies, 29(12) 1495-1519.

Chattananon, A., Lawley, M., Supparerkchaisakul, N. \& Leelayouthayothin, L. (2008). Impacts of a Thai cause-related marketing program on corporate image International Journal of Emerging Markets, 3(4), 348-363.

Chouliaraki, L. (2006). The Spectatorship of Suffering. London: Sage.

Dean, C.J. (2004). The Fragility of Empathy. Ithaca: Cornell University Press.

Deleuze, G. (2005). Cinema 1. New York: Continuum.

Ellis, J. (2002). Seeing Things. Television in the Age of Uncertainty. London: I.B. Tauris Publishers.

Frello, B. (2003). Identiteter på spil. Medierne og krigen i Kosovo. Copenhagen: Forlaget Politiske Studier.

Harvey, J.A. \& Strahilevitz, M.A. (2009). The Power of Pink: Cause-Related Marketing and the Impact on Breast Cancer. Journal of the American College of Radiology, 6(1), 26-32. 
Jørgensen, M.W. \& Phillips L. (1999). Diskursanalyse: som teori og metode. Copenhagen: Roskilde Universitetsforlag/ Samfundslitteratur.

Kotler, P. \& Lee, N. (2005). Corporate Social Responsibility. Doing the Most Good for your Company and Your Cause. Hoboken: John Wiley \& Sons.

Katsioloudes, M., Grant, J. \& McKechnie, D.S. (2007). Social Marketing: Strengthening Company-Customer Bonds. The Journal of Business Strategy, 28(3), 56-64.

Kress, G. \& Leeuwen T. (2001). Multimodal Discourse. The modes and media of contemporary communication. London: Arnold.

Lang, Gabriel, Y. \& Lang, T. (2006). The Unmanageable Consumer. (2 ${ }^{\text {nd }}$ ed.). London: Sage.

Larson B.V., Flaherty K.E, Zablah A.R., Brown T.J. \& Wiener J.L. (2008). Linking cause-related marketing to sales force responses and performance in a direct selling context. Academy of Marketing Science, 36(2), 271-277.

Laclau, E. \& Mouffe C. (2001). Hegemony and Socialist Strategy. Towards a Radical Democratic Politics. (2 ${ }^{\text {nd }}$ ed.). London: Verso.

Lévinas, E. (1996). Totalitet og uendelighed. Copenhagen: Hans Reitzels Forlag.

Nickel, P.M. \& Eikenberry, A.M. (2009). A Critique of the Discourse of Marketized Philanthropy. American Behavioral Scientist, 52(7), 974-989.

Paine, L.S. (2003). Value Shift. McGraw Hill.

Ponte, S., Richey, L.A. \& Babb, M. (2009). Bono's Product (RED) Initiative: Corporate Social Responsibility that Solves the Problems of 'Distant Others'. Third World Quarterly, 30(2), 301-317.

Salzer-Mörling, M. \& Strannegård, L. (2007). Silence of the Brands. European Journal of Marketing, 38(1/2), 224-238.

Silverstone, R. (2007). Media and morality: On the rise of the mediapolis. Cambridge: Polity.

Sontag, S. (2003). Regarding the Pain of Others. New York: Farrar, Straus and Giroux.

Sørensen, M. (2004). Den Politiske Forbruger. Kbh.: Hans Reitzel.

Szmigin, I., Carrigan, M. \& O'Loughlin, D. (2007). Integrating Ethical Brands into our Consumption Lives. Journal of Brand Management, 13(7), 396-409.

Tomlinson, J. (1999). Globalization and Culture. Cambridge: Polity.

Tsai, S-P. (2009). Modelling strategic management for cause-related marketing. Marketing intelligence \& planning, 27(5), 649-665.

Youn, S. \& Hyuksoo, K. (2008). Antecedents of Consumer Attitudes toward Cause-Related Marketing. Journal of Advertising Research, 48(1), 123-137.

\section{Internet sources}

www.buylesscrap.com

www.joinred.com

www.seattletimes.com

www.sos-borneby.dk

www.youtube.com 


\section{Notes}

1 The article is inspired by many fruitful discussions in a research group, which has precisely been dealing with new ways of handling global responsibility through consumption. The group consists of scholars from the Scandinavian Department at Aarhus University (Britta Timm Knudsen, Dorthe Refslund Christensen, Carsten Stage) and Aarhus School of Business (Anne Ellerup Nielsen, Trine Johansen, Sophie Esmann Andersen). Aarhus University Research Fond (AUFF) financially supports the research group, grant no. 20106.

2 Partner brands include (at the time of the analysis, winter 2009): American Express, Apple, Bugaboo, Converse, Dell, Armani, GAP, Hallmark, Nike and Starbucks (http://www.joinred.com/Learn/Partners. aspx (visited 17.12.2009)).

3 See for example: http://epn.dk/international/article25022.ece, http://adage.com/article?article id=115287, http://www.mpdailyfix.com/2007/03/rediculess.html.

4 According to (RED), purchases of (RED) products have contributed 140 million dollars to The Global Fund (http://www.joinred.com/Learn/HowRedWorks/GlobalFund1.aspx (visited 17.12.2009)).

5 For example: Lizard King Red Campaign, posted by CaptainPink, Dec. 2006: http://www.youtube. com/watch?v=KfOls3Fhol4;

The Righteous Red Rage Squard, posted by Redalertcops, Dec. 2006; http://www.youtube.com/ watch?v=PGXhhzurkXQ;

(RED), posted by salilmehta10, June 2007: http://www.youtube.com/watch? $v=R 1 k 8563 t 25 \mathrm{~g} \&$ feature $=$ related);

Product (Red) Aids Video, posted by Purpleprincess87, April 2007: http://www.youtube.com/watch?v $=$ p2WvCZEfpaQ\&feature $=$ related).

6 Because You Choose (Red), posted by Joinred, Nov 2007: http://www.youtube.com/watch?v=Se195B T3rPE\& feature $=$ channel.

7 The Lazarus Effect, posted by Joinred, Nov 2009: http://www.youtube.com/watch?v=W4GMYQx58O E\&feature=player_embedded.

8 (RED) Ambassador Christy Turlington in Africa, posted by Joinred, May 2007 http://www.youtube. com/watch?v=v-jZeiC8EUw

(RED) in Ghana with Elle Macpherson and Rocky Dawuni, posted by Joinred, July 2007: http://www. youtube.com/watch? $v=$ aqXtQ3gYfnY\&feature=channel.

9 American Express ${ }^{\oplus}$ RED, posted by AmericanExpressRED, Sep. 2006: http://www.youtube.com/ watch? $\mathrm{v}=\mathrm{dEB} 5 \mathrm{GWf}-\mathrm{QNg}$,

Natasha Bedingfiels gives a tour of Grammys' (Gap) RED Room, posted by Joinred, Feb. 2007: http:// www.youtube.com/watch?v=NTb_3Ppp194,

Joss Stone and Common join (RED), posted by Joinred, June 2007: http://www.youtube.com/ watch?v=ztikJFBRBtc.

10 The Lazarus Effect, posted by Joinred, Nov 2007: http://www.youtube.com/watch?v=W82SoRp9Au4.

11 On the latest version of the homepage, (RED) actually stresses the possibility of donating to the fund directly (http://www.joinred.com/Learn/HowRedWorks/GlobalFund1.aspx).

12 In his everyday life, Keseme Ole Parsapaet lives in the village Oloomunyi outside Kenya's capital, Nairobi. He herds goats and cattle, and once in a while works as a model for one of Kenya's oldest model agencies. With the money he received for his short appearance in the (RED) campaign, he has built a tin hut, bought more goats and cattle, and plans to buy a pick-up truck (see: http://seattletimes. nwsource.com/html/nationworld/2003631862_cowherd23.html). 
Article: Consumption that matters

Sophie Esmann Andersen

Assistant Professor, Ph.D.

Centre for Corporate Communication,

Aarhus University, Denmark

sea@asb.dk

Carsten Stage

Assistant Professor, Ph.D.

Scandinavian Department, Aarhus University,

Denmark

norcs@hum.au.dk 